\section{The Uncertainty Principle}

Is a lecture delivered to the Physical and Chemical Society of University College, Nottingham, on February 4, Prof. E. Schrödinger directed attention to the difficulties and contradictions which arise from attempts to unite quantum theory with geometry and with the theory of relativity. Although the first researches on wave mechanics used the relativity ideas, they are really in flat contradiction to them. The theory of relativity supposes that rods and clocks can be used to measure exact lengths and times, and that in some way velocities can also be measured accurately. Unfortunately, Heisenberg's uncertainty principle, which appears to be inherent in quantum mechanies, lays down that simultaneous accurate measurements of position and velocity are impossible. Moreover, the regulation of a elock is not possible to more than a limited degree of accuracy, except when the clock is infinitely heavy. Similar considerations forbid us to apply our ideas of Euclidean geometry, based upon ideal rigid measuring rods, to small physical regions. Physicists have at least as much confidence in the special theory of relativity as in quantum theory; the problem of devising a unified theory appears to be still unsolved.

\section{A French Chemical News Service}

WE have before us the first number of Les Nouvelles de la Chimie - a new monthly paper issued in Paris. It resembles in its general appearance a daily paper, a fact which may seem unusual in England; in France there exist already several medical news journals having the same format. The front page of the new journal contains news items, interviews and similar topical material; on the second page we find a review of general scientific activities in the universities and laboratories, while the third and fourth pages are devoted to general technical and economic information. The editor of the new paper is M. Jean Gérard, the active director of the Maison de la Chimie and its Centre of Documentation. We understand that if the new venture fulfils the expectations of its promoters, it will develop into a weekly and finally into a daily news service covering not only the field of ehemistry but also that of science in general.

\section{Baffin Island Survey}

THE annual report of the Canadian Department of Marine for the fiscal year 1933-34 contains some interesting information respecting the operations of the Canadian Hydrographic Service during the period under review. Among other technical observations, the Service carried out a survey of the Baffin Island coast, of which the following extract is a partial description. "In aspect, the south-eastern coast of Baffin Island is very bleak, bare rugged hills of gneiss and granite rising to elevations about 600 feet close to the sea and to greater heights inland. The ragged shore is broken by numerous fiord-like inlets, but from Pritzler Harbour to Barrier Inlet, 45 miles north-northwestward, the shore is fronted by many islets, rocks and shoals of a most dangerous character. The 50-fathoms contour, which lies at an average distance of 3 miles off the islands, should be considered the danger line. The country is quite uninhabited except for some Eskimos who travel gregariously along the coast in whaleboats (omiaks). These natives appear to be of a very good typehealthy, honest and well adapted to the rigours of the country. Their habitat is both the north and south coasts of the long peninsula which separates Frobisher bay from Hudson strait. The small, swift rivers which flow into the heads of the inlets are well stocked with a fine species of salmon trout weighing up to $8 \mathrm{lbs}$.; this food, together with seal, constitutes their chief diet. At certain times a caribou hunt takes place and the hunters travel inland for several days to secure fresh meat. In addition, the country also provides aquatic fowl, ptarmigan, arctic hare and an occasional walrus or polar bear."

\section{Reversing Falls at Barrier Inlet}

After recording the absence of good ship harbourage between Pritzler Harbour and Barrier Inlet, the report of the Canadian Department of Marine goes on to describe the physical features of the latter, which is an arm of the sea extending 12 miles inland. At the entrance, it has a width of about a mile and a half, but two miles inside, the width contracts to three quarters of a mile. The channel is still further constricted at this point by a number of rocky islets, connected at low stages of the tide and leaving only two narrow passage-ways less than a hundred yards wide. "The free flow of the tide in and out of the inlet being thus constricted at the narrows, a 'head' of water is formed and creates a reversing falls. At the time of low tide on October 1 , there was a sheer outward waterfall $8 \frac{1}{2}$ feet in height, and the lowering of the fiordal waters continued for a space of $2 \frac{1}{2}$ hours whilst the tide was rising outside at the foot of the cataract. Slack water occurred for a few moments when the flood tide reached the elevation of the water in the fiord but almost immediately the inward rush of water formed whirlpools and great eddies and soon waves, 6 feet high, careened wildly from side to side. A boat attempting to pass through at such time would be engulfed."

\section{American Museum of Natural History: New Director}

According to Science of January 15, Dr. George H. Sherwood has resigned his post as director of the American Museum of Natural History to give his entire time to the School Service Section as curatorin-chief of education. Dr. Sherwood will remain honorary director of the museum. Dr. Roy Chapman Andrews will succeed Dr. Sherwood as the active head of the museum. As leader of the Central Asiatic Expeditions of the American Museum of Natural History, Dr. Andrews took his first expedition into the field in 1916 to work in the territory of Tibet, South-west China and Burma. His second expedition went into North China and Outer Mongolia in 1919, and the third expedition has worked in Central Asia, especially in Mongolia, since 1921, 